\title{
Atypical Progesterone Profiles and Fertility in Swedish Dairy Cows
}

\author{
K.-J. Petersson, ${ }^{\star 1}$ H. Gustafsson, $†$ E. Strandberg, ${ }^{*}$ and B. Berglund ${ }^{*}$ \\ *Department of Animal Breeding and Genetics, Swedish University of Agricultural Sciences, Centre for Reproductive Biology in Uppsala, \\ PO Box 7023, SE-750 07 Uppsala, Sweden \\ †Swedish Dairy Association, PO Box 7054, SE-750 07 Uppsala, Sweden
}

\begin{abstract}
The incidence of normal and atypical progesterone profiles in Swedish dairy cows was studied. Data were collected from an experimental herd over $15 \mathrm{yr}$, and included 1,049 postpartum periods from 183 Swedish Holstein and 326 Swedish Red and White dairy cows. Milk progesterone samples were taken twice weekly until initiation of cyclical ovarian activity and less frequently thereafter. Progesterone profiles were 1) normal profile: first rise in milk progesterone above the threshold value before d 56 postpartum, followed by regular cyclical ovarian activity $(70.4 \%) ; 2$ ) delayed onset of cyclical ovarian activity: low milk progesterone the first $56 \mathrm{~d}$ postpartum (15.6\%); 3) cessation of cyclical ovarian activity: ovarian activity resumed within $56 \mathrm{~d}$ postpartum, but ceased for a period of $14 \mathrm{~d}$ or more (6.6\%); and 4) prolonged luteal phase: ovarian activity resumed within $56 \mathrm{~d}$ postpartum, but milk progesterone remained elevated in the nonpregnant cow for a period of $20 \mathrm{~d}$ or more (7.3\%). Swedish Holsteins had 1.5 times higher risk of atypical profile than Swedish Red and Whites. Risk of atypical profiles was 0.5 and 0.7 times lower for older cows compared with first-parity cows; 2.3 times higher for cows in tie-stalls compared with those in loose housing; 2.6 times higher for cows calving during winter compared with summer; 0.5 times lower for cows in earlier (1994-1999) calving-year groups compared with the most recent (2000-2002); 2.5 times higher for cows with planned extended calving interval compared with conventional calving interval; and 2.2 times higher for an atypical profile in previous lactation compared with a normal profile. Cows with atypical profiles had a 15-d increase in interval from calving to first artificial insemination and an 18-d increase in interval from calving to conception. Progesterone samples taken within the first $60 \mathrm{~d}$ postpartum were used to calculate the percentage of samples above the threshold value of luteal activity. This measure had a significantly different mean in profiles and can be used to separate
\end{abstract}

Received October 5, 2005.

Accepted February 2, 2006.

${ }^{1}$ Corresponding author: karl-johan.petersson@hgen.slu.se delayed onset of cyclical ovarian activity profiles and prolonged luteal phase profiles from normal. Thereby, it may be a more effective tool than measurements based only on the onset of ovarian cyclical activity in genetic evaluation of early postpartum fertility in dairy cows.

Key words: progesterone profile, fertility, dairy cow

\section{INTRODUCTION}

Examination of milk progesterone profiles offers an objective method for the characterization of the postpartum ovarian activity in dairy cows. A normal profile consists of a period of low progesterone after calving followed by increasing concentrations that are indicative of the first postpartum ovulation. Thereafter, a period of falling and rising progesterone, reflecting ovarian cyclical activity, follows until pregnancy (Lamming and Bulman, 1976). Deviations from a normal progesterone pattern were associated with decreased fertility in the dairy cow (Bulman and Wood, 1980). Early onset of ovarian cyclical activity increased the probability of an early AI after calving, shortened the interval between calving and conception, increased the conception rate, and reduced the number of services per conception (Darwash et al., 1997).

Lower fertility in dairy cows and increasing production levels have been reported in several countries. Royal et al. (2000) reported a decline in pregnancy rate to first AI of 1\% per year during the period from 1975 to 1998 in Great Britain. In the United States, Lucy (2001) reported an increase in the number of AI per conception from 1.75 in 1970 to 3.0 in 1999, and an increase in calving interval from 13.5 to $14.7 \mathrm{mo}$. In Sweden, there has been a slightly negative phenotypic trend in the fertility of the dairy cows; that is, the calving interval has increased from 12.6 mo in 19741975 to 13.2 mo in 2002-2003 (Swedish Dairy Association, 2004).

It is likely that endocrine measures based on progesterone profiles have been altered with selection for high milk yield. Opsomer et al. (1998) reported a longer interval from calving to first ovulation in first-parity cows than observed in earlier studies. A high incidence of atypical progesterone profiles was reported from Bel- 
gium (Opsomer et al., 2000). Furthermore, an increase in atypical patterns of milk progesterone profiles from 32 to $44 \%$ was observed by Royal et al. (2000), who compared data from 1975 to 1982 with data from 1995 to 1998.

The primary aim of this study was to assess the incidence of normal and different atypical progesterone profiles in the 2 main breeds of dairy cattle in Sweden. Secondly, we assessed relationships between progesterone profiles, and environmental effects, fertility disorders, traditional reproductive events, and other progesterone-based fertility measures.

\section{MATERIALS AND METHODS}

\section{Animals}

Data were collected between December 1987 and December 2002 in the experimental herd of the Department of Animal Breeding and Genetics, Swedish University of Agricultural Sciences (Uppsala, Sweden). A total of 1,049 lactations were included from 509 dairy cows of Swedish Red and White (SRW, $\mathrm{n}=326$ cows) and Swedish Holstein (SH, $\mathrm{n}=183$ cows) breeds. Milk production was calculated in kilograms of ECM assessing fat, protein, and lactose contents, using the method of Sjaunja et al. (1990). Average 305-d ECM production in the last year of the study was $8,580 \mathrm{~kg}$ for the SRW cows and 9,870 kg for the SH cows. During the data collection period, the increase in 305-d ECM production was $1,500 \mathrm{~kg}$ for the SRW cows and $2,120 \mathrm{~kg}$ for the $\mathrm{SH}$ cows. These figures approximate the national average for the 2 breeds in Sweden. For this study, we calculated kilograms of ECM produced during the first 60 DIM. Cows were in their first to 10th lactations, but were grouped as first, second, and $\geq$ third lactation. From 1994 onward, cows were subjected to a calving interval trial, in which they were inseminated for planned calving intervals of either 12 or 15 mo. A thorough description of that trial was published in Ratnayake et al. (1998) and Rehn et al. (2000). From 1985, the SRW cows were subjected to a selection trial on high or low milk fat content, but with the same energy content in the milk (Janson and Ahlin, 1992). The effect of the selection trial was tested in all models, but the findings were omitted, because there were no significant differences between the selection lines.

\section{Management}

Two housing systems were used at the experimental farm: tie-stalls or a loose housing system. Records of housing were available from 1992 to 2001; before 1992, the experimental herd was kept at another location at which all the animals were tied. All cows were milked twice daily, at 0600 and $1515 \mathrm{~h}$, in individual stalls for the tied cows and in a milking parlor for the loosehoused cows.

Cows were fed according to daily requirements of $\mathrm{ME}$, protein, and minerals following Swedish standards (Spörndly, 1999), as conducted by Rehn et al. (2000). Cows were fed the entire ration individually in the tiestalls. In the loose housing barn, only concentrates were fed individually. From May to September each year, cows were kept on pasture during daytime. During the pasture period, additional concentrates and roughage were fed indoors.

Detection of estrus was conducted visually 3 times daily at fixed times. The strength of estrous symptoms was scored according to the following scale: $0=$ no estrus, $1=$ uncertain, $2=$ weak, $3=$ normal, $4=$ strong, and, from 1995 onwards, 5 = very strong, based on occurrence of different signs such as bellowing, mounting behavior, vulvar swelling, licking, and vulvar discharge. Cows with planned calving intervals of 12 and 15 mo were not inseminated before 50 and $140 \mathrm{~d}$ postpartum, respectively. A maximum of $5 \mathrm{AI}$ were allowed per breeding period, with breeding periods restricted to a maximum of $130 \mathrm{~d}$ between first and last AI. Thereafter, cows were culled because of infertility. All inseminations were performed by experienced AI technicians.

Three different reproductive disorders were included in our study: anestrus, ovarian cysts, and endometritis. A veterinarian examined the reproductive health of all cows in wk 3 and 6 postpartum. Cows were considered anestrus if no corpus luteum or cystic structures were recorded on the ovaries; this was later confirmed by low progesterone concentrations recorded over more than $10 \mathrm{~d}$. Ovarian cyst was diagnosed based on the presence of cystic structures of 20 to $25 \mathrm{~mm}$ based on rectal palpation, the lack of a corpus luteum, combined with no clinical signs of ovarian cyclical activity reported by the barn staff. The lack of luteal activity was later confirmed by low progesterone recorded over more than $10 \mathrm{~d}$. We did not differentiate between luteal and follicular cysts, because they were treated in the same manner. Cows were regarded as having endometritis in the presence of white or whitish-yellow mucopurulent vaginal discharge from the vulva more than $3 \mathrm{wk}$ after calving, as observed by the barn staff. The discharge characteristics were confirmed during rectal palpation. Moreover, these findings were combined with a thickwalled uterus, in many cases defectively involuted. Anestrus cows were treated with a progesterone-releasing intravaginal device (EAZI-breed CIDR, InterAg, Hamilton, New Zealand) for $11 \mathrm{~d}$, or with an i.m. injection of $10 \mu \mathrm{g}$ of $\mathrm{GnRH}$ analog (buserelin acetate; Receptal, Intervet, Boxmeer, The Netherlands). In cows with a planned calving interval of $12 \mathrm{mo}$, treatment was not 
initiated until at least $50 \mathrm{~d}$ after calving. In the 15mo calving interval group, treatment started no earlier than $130 \mathrm{~d}$ postpartum. Cystic cows were treated with an i.m. injection of $10 \mu \mathrm{g}$ of the same GnRH analog, but not until at least $42 \mathrm{~d}$ postpartum. Cows with signs of endometritis were treated from d 30 postpartum onwards by i.m. injections of $25 \mathrm{mg}$ of dinoprost (prostaglandin $\mathrm{F}_{2 \alpha}$; Dinolytic, Orion Animal Health, Espoo, Finland). Not all diagnoses of a reproductive disorder were followed by treatment. Reflecting this, the lactations were assigned to one of the following categories: 1) healthy: no diagnosis of the particular disorder and the animal was assumed healthy during the current lactation period; 2) diagnosed: a diagnosis of the disorder was made, but no treatment was undertaken; and 3) treated: a positive diagnosis followed by treatment. Four veterinarians performed reproductive health control using the same protocols for diagnosis and treatment during the experimental period.

All treatments for diseases were recorded in the research protocol. The associations between type of progesterone profile and the most common diseases (mastitis, lameness, and puerperal paresis) occurring before first AI were studied. For diseases other than reproductive disorders, only 2 categories, healthy vs. treated, were used.

Data on live weights collected in the first and eighth week were used to measure BW change postpartum. Weight change was classified as low ( $\leq 6 \mathrm{~kg}$ of loss), normal (7 to $49 \mathrm{~kg}$ of loss), and high ( $\geq 50 \mathrm{~kg}$ of loss). The date when the cow was dried off was used to calculate dry period length in the previous lactation. Dry periods were classified as short ( $\leq 46 \mathrm{~d}$ ), normal ( 47 to $67 \mathrm{~d}$ ), and long ( $\geq 68 \mathrm{~d}$ )

\section{Fertility Measures}

Milk sampling for progesterone analysis started during the second week following parturition. Milk was sampled twice weekly until ovarian cyclical activity was detected. Sampling was then reduced to once weekly until first AI. Progesterone was analyzed in whole milk. The sample (about $5 \mathrm{~mL}$ of milk) was taken within 60 min after milking, collected into tubes containing 100 $\mu \mathrm{L}$ of preservative (Bronopol $2 \%+$ methylene blue $0.05 \%$ ) and stored at $4^{\circ} \mathrm{C}$ until radioimmunoassay. Three different kits were used during the study period. From the start of data collection until 1995, Farmose (Orion Diagnostica) was used. The company then introduced a new assay, Spectra, which was used until 1998. From 1998, a Coat-A-Count kit was used (Diagnostic Products Corporation, Los Angeles, CA). The intraassay variation was below $10 \%$ for all $3 \mathrm{kits}$ and the corresponding interassay variation was below 16\% (Ratnay- ake et al., 1998). Progesterone observations from estimated day of ovulation were used to set limits for luteal activity for each of the 3 kits. Day of ovulation was estimated as the day after detection of estrus (score: 3 to 5) or the day before onset of metestrus bleeding. The progesterone concentration that $95 \%$ of these estimated days of ovulation fell below was set as the lower limit for luteal activity. The limits used were 8.0, 3.0 and 1.3 $\mathrm{nmol} / \mathrm{L}$ for the Farmose, Spectra, and Coat-A-Count kits, respectively.

Progesterone concentrations were plotted against days postpartum to establish individual lactation profiles until first AI was performed. The profiles were then categorized according to a modified definition given by Opsomer et al. (2000), into 1) normal profile, 2) delayed onset of cyclical ovarian activity (delayed cyclicity), 3) cessation of cyclical ovarian activity (cessation of cyclicity), and 4) prolonged luteal phase (Table 1 and Figure 1). Double classification of profiles occurred in 23 lactations. All analyses were conducted using the alternative classified profiles and these analyses did not change our results. Profiles were excluded if the sampling scheme was not followed; that is, the interval between 2 consecutive samples was $\geq 10 \mathrm{~d}$ before first $\mathrm{AI}$, and 92 profiles were excluded for this reason.

The progesterone profiles were used to derive early, endocrine-based fertility measurements. The first postpartum progesterone value above the threshold value for the 3 different kits, preceded by low progesterone, was used to define the interval from calving to commencement of luteal activity (CLA). All progesterone samples taken within the first $60 \mathrm{~d}$ postpartum were used to calculate the percentage of samples above the limit, and hence, percentage luteal activity (PLA). Recordings of observations of estrus were used, together with the progesterone profiles, to decide the day of first ovulatory estrus (FOE). As long as progesterone was both low and increased above the limit within $10 \mathrm{~d}$, FOE was regarded as having occurred either the day after an observation of estrus (score 2 to 5 ) or the day before a metestrus bleeding.

Records of AI were used to calculate interval from calving to first AI (CFI), calving to conception interval (CCI), and interval from pregnancy to first AI (PFI). When an AI was followed by a repeat AI within $6 \mathrm{~d}$, the first AI was omitted.

\section{Statistical Methods}

The influence of various fixed effects on type of progesterone profile was analyzed with a multinomial model in the multilog procedure in SUDAAN (Research Triangle Institute, 2004), implementing a generalized logit model due to the nominal distribution of the pro- 
Table 1. Description and incidence of the progesterone profiles in Swedish Holstein and Swedish Red and White dairy cows

\begin{tabular}{lll}
\hline Type of profile & Description & $\mathrm{n}(\%)$ \\
\hline Normal & First rise in progesterone before d 56 postpartum, followed by regular cyclicity & $739(70.4)$ \\
Delayed cyclicity & Low progesterone for the first 56 d postpartum & $164(15.6)$ \\
Cessation of cyclicity & Normal start of cyclicity, but interrupted for at least 14 d with low progesterone levels & $69(6.6)$ \\
Prolonged luteal phase & Normal start of cyclicity, but with high progesterone levels for at least 20 d & $77(7.3)$ \\
\hline
\end{tabular}

gesterone profiles because the 4 different profiles have no natural ordering. Moreover, the 3 atypical profiles were merged into a single category to allow a binomial analysis of the data. This model was analyzed with the multilog procedure, but using a cumulative logit link due to the ordinal response. The effect of the individual cow was treated as a random effect by utilizing the NEST statement in SUDAAN, in which each individual cow is treated as a cluster.

Model B1 ( $n=1,049)$ used for binomial analysis included fixed effects of breed (SRW and SH); parity (1, 2 and $\geq 3$ ); housing (tied, loose, old barn, or no information); calving season (winter and summer); calving interval group; anestrus (healthy, diagnosed, treated); ovarian cysts (healthy, diagnosed, treated); endometritis (healthy, diagnosed, treated); calving year group
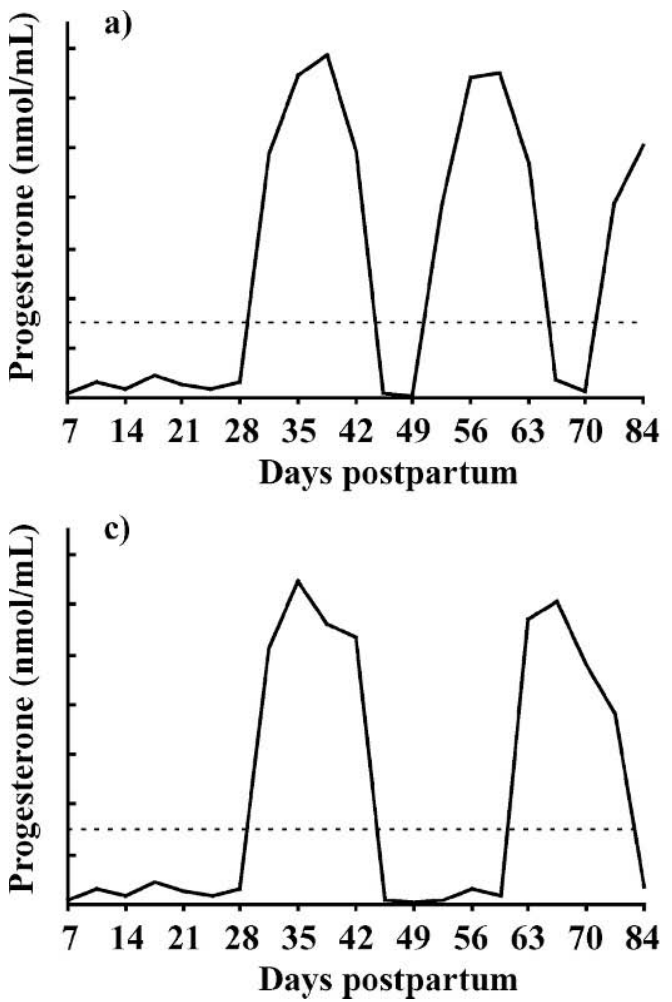

(1987-1993, 1994-1996, 1997-1999, 2000-2002); and lameness (yes or no). The distribution of atypical progesterone profiles over time was analyzed by dividing the data into 4 calving year groups with as similar number of lactations as possible. Therefore, the first calving year group covers a longer period than the other 3 calving year groups. The calving interval group had 5 distinct classes: first and later lactation, respectively, in the 12-mo calving interval trial; first and later lactation, respectively, in the 15-mo calving interval trial; and a group for cows not in the calving interval trial.

For the multinomial analysis, model M1 was used, which included the same covariates as model B1. However, this model caused singularity problems because no cases with endometritis had cessation of cyclicity profiles. Therefore, all records with cessation of cyclicity
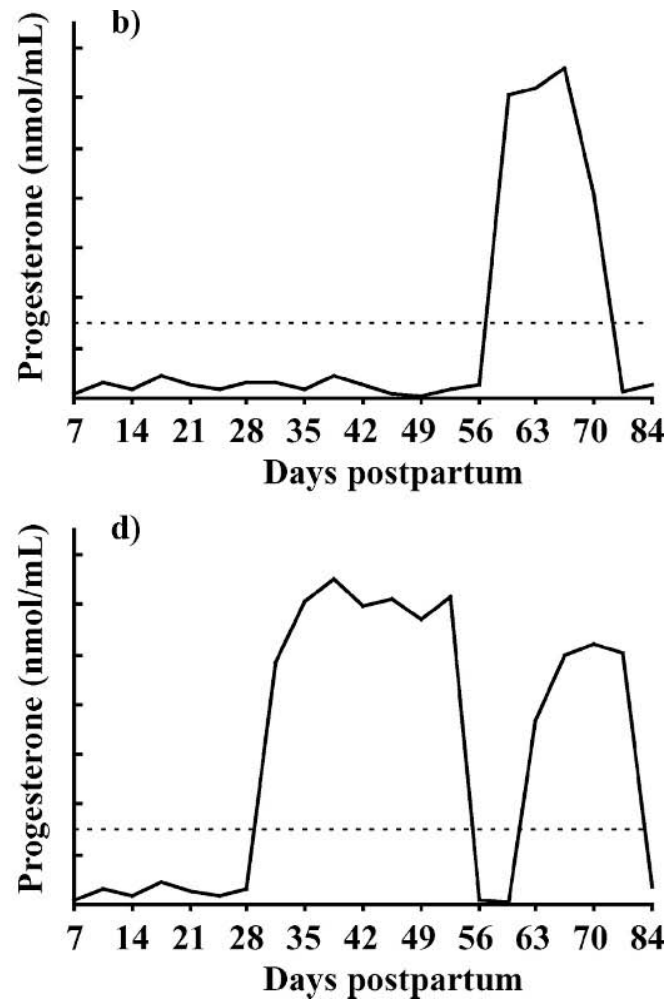

Figure 1. Schematic illustration of the different progesterone profiles for Swedish Holstein and Swedish Red and White dairy cows: a) normal profile, b) delayed cyclicity, c) cessation of cyclicity, and d) prolonged luteal phase. Solid lines represent the progesterone level; dotted lines represent the limit of progesterone for luteal activity. 
were deleted and 980 observations were included in the analysis. The full data set $(n=1,049)$ was analyzed using model M1a, in which the covariate of endometritis was excluded from model M1.

For model B2 $(n=518)$ of binomial analysis, the effects of parity and calving interval group were omitted from model B1 and the effects of type of progesterone profile during the previous lactation and the effect of dry period length in the previous lactation were added. Model M2 $(\mathrm{n}=518)$ for multinomial analysis included the same effects as B2, but the effects of endometritis and anestrus were omitted because of convergence problems.

In model B3 ( $\mathrm{n}=719)$ for binomial analysis, BW change was added to model B1 and housing system was excluded, due to convergence problems. When BW change was used as a covariate in the multinomial analysis, model M3 ( $\mathrm{n}=719)$ was used with housing system, endometritis, and calving interval omitted from model M1a, due to convergence problems.

Covariates tested in the statistical models, but omitted due to no significance were mastitis (treated or healthy), puerperal paresis (treated or healthy), and kilograms of ECM produced during the first 60 DIM.

The association between type of progesterone profile and traditional fertility measurements, CFI $(\mathrm{n}=671)$, CCI ( $\mathrm{n}=548)$, and PFI ( $\mathrm{n}=671$ ), was analyzed with mixed linear models using PROC MIXED (SAS Institute, 2001). The model used by Petersson et al. (2006) included a random effect of cow together with fixed effects of breed (SRW and SH); parity (1, 2, and $\geq 3$ ); housing (tied, loose, old barn, or no information); calving season (winter and summer); calving year group (1987-1993, 1994-1996, 1997-1999, 2000-2002); lameness (yes or no); mastitis (yes or no); kilograms of ECM produced during the first $60 \mathrm{DIM}$; and type of progesterone profile (normal, delayed cyclicity, cessation of cyclicity, and prolonged luteal phase). For these analyses, all cows with a planned calving interval of 15 mo were excluded, because the longer voluntary waiting period would have affected CFI and CCI. We have shown that these mixed linear models are robust for analyses of these traits, CFI, CCI, and PFI, and obtained the same results as with transformed CFI and CCI and logistic regression for PFI (Petersson et al., 2006).

\section{RESULTS}

For the binomial analysis, all profiles of delayed cyclicity, cessation of cyclicity and prolonged luteal phase were merged into one category called atypical profile. This category incorporated 310 profiles corresponding to $29.6 \%$ of all profiles. The binomial analysis revealed no statistically significant association with dry period length in previous lactation (Table 2). The results presented in Table 3 are derived from the multinomial analyses; all are expressed as the risk of having 1 of the 3 atypical profiles rather than a normal profile.

The effects of parity, housing, calving year group, lameness, weight loss, and previous dry period length were only statistically significant for the profiles of delayed cyclicity in Table 3. Thus, the results from the binomial model were mostly explained by this type of atypical profile. Results from the multinomial model showed that $\mathrm{SH}$ had a statistically significant higher risk of having prolonged luteal phase. Calving season, calving interval group, and type of progesterone profile in previous lactation had statistically significant associations with both delayed cyclicity and cessation of cyclicity. If the cow had delayed cyclicity or cessation of cyclicity in the previous lactation, there was a statistically significant higher risk of displaying the same profile again. The results for the fertility disorders in the binomial analysis were associated with various atypical profiles as shown in Table 3.

The association between type of profile with more traditional fertility measurements (CFI, CCI, and PFI) is shown in Table 4. The values are shown for each type of profile individually and for the aggregate of all atypical profiles into a single group. The association with PFI was not statistically significant.

Table 5 shows the means per type of profile for CLA, FOE, and PLA. These were all associated with various types of progesterone profiles. There was a statistically significant delayed CLA in cows with delayed cyclicity. This was reflected in FOE, which was significantly later if the cow had a delayed cyclicity profile. Cows with cessation of cyclicity had a significantly later FOE than cows with a normal profile. The mean of PLA per type of profile was significantly different between all of the profiles.

\section{DISCUSSION}

The proportion of atypical progesterone profiles was considerably lower than that in recent studies from Belgium (Opsomer et al., 2000) and Great Britain (Royal et al., 2000). It was, however, higher than the $22 \%$ of atypical profiles reported by Bulman and Wood (1980). The definitions of atypical profiles used here are slightly different from those in other studies; that is, with a different number of days used in the definitions, which make the results not directly comparable. However, fertility has been included in the Swedish breeding evaluation scheme since the 1970s (Lindhé et al., 1994), and the low proportion of atypical profiles in our data set is probably an effect of selection for improved fertility. The higher risk of atypical profiles, explained 
Table 2. Binomial model with resulting odds ratios, and lower and upper 95\% confidence interval (CI) limits for atypical vs. normal profile and different systematic environmental effects for Swedish Holstein and Swedish Red and White dairy cows ${ }^{1}$

\begin{tabular}{|c|c|c|c|c|}
\hline Independent effect & Class & $\mathrm{n}$ & Odds ratio & $\begin{array}{l}\text { Lower-upper } \\
95 \% \text { CI }\end{array}$ \\
\hline Intercept & & & 0.10 *** & $0.04-0.23$ \\
\hline \multirow[t]{2}{*}{ Breed } & Swedish Red and White & 702 & 1 & \\
\hline & Swedish Holstein & 347 & $1.50^{*}$ & $1.06-2.12$ \\
\hline \multirow{3}{*}{ Parity } & First & 433 & 1 & \\
\hline & Second & 283 & $0.48 * *$ & $0.28-0.82$ \\
\hline & $\geq$ Third & 333 & 0.66 & $0.38-1.13$ \\
\hline \multirow[t]{4}{*}{ Housing } & Loose & 292 & 1 & \\
\hline & Tied & 412 & $2.29 * * *$ & $1.49-3.51$ \\
\hline & Old barn & 199 & $2.06^{*}$ & $1.09-3.92$ \\
\hline & No information & 146 & 1.36 & $0.76-2.46$ \\
\hline \multirow[t]{2}{*}{ Calving season } & Summer & 529 & 1 & \\
\hline & Winter & 520 & $2.55^{* * *}$ & $1.84-3.53$ \\
\hline \multirow[t]{4}{*}{ Calving year group } & 2000 to 2002 & 233 & 1 & \\
\hline & 1997 to 1999 & 247 & $0.49 *$ & $0.27-0.87$ \\
\hline & 1994 to 1996 & 261 & $0.54^{*}$ & $0.29-0.99$ \\
\hline & 1987 to 1993 & 308 & 1.09 & $0.43-2.73$ \\
\hline \multirow[t]{5}{*}{ Calving interval } & $12 \mathrm{mo}$, later lactations & 181 & 1 & \\
\hline & 15 mo, later lactations & 127 & $2.47 * *$ & $1.31-4.67$ \\
\hline & 12 mo, first lactation & 161 & 0.95 & $0.44-2.06$ \\
\hline & $15 \mathrm{mo}$, first lactation & 140 & 1.70 & $0.80-3.63$ \\
\hline & Not in trial & 440 & 1.46 & $0.67-3.21$ \\
\hline \multirow[t]{3}{*}{ Anestrus } & Healthy & 959 & 1 & \\
\hline & Diagnosed & 21 & $35.69 * * *$ & $8.16-156.08$ \\
\hline & Treated & 69 & $16.72^{* * * *}$ & $8.83-31.66$ \\
\hline \multirow[t]{3}{*}{ Ovarian cysts } & Healthy & 886 & 1 & \\
\hline & Diagnosed & 112 & 1.34 & $0.82-2.21$ \\
\hline & Treated & 51 & $7.01^{* * * *}$ & $3.53-13.94$ \\
\hline \multirow[t]{3}{*}{ Endometritis } & Healthy & 982 & 1 & \\
\hline & Diagnosed & 14 & 0.61 & $0.13-2.86$ \\
\hline & Treated & 53 & $3.53 * * *$ & $1.84-6.78$ \\
\hline \multirow{2}{*}{ Lameness } & Healthy & 985 & 1 & \\
\hline & Treated & 64 & 1.83 & $0.98-3.44$ \\
\hline \multirow[t]{3}{*}{ Weight $\operatorname{loss}^{2}(\mathrm{~kg})$} & $\leq-6$ & 182 & 0.73 & $0.43-1.23$ \\
\hline & -49 to -7 & 345 & $0.64^{*}$ & $0.41-1.00$ \\
\hline & $\geq-50$ & 192 & 1 & \\
\hline \multirow[t]{3}{*}{ Previous dry period ${ }^{3}(\mathrm{~d})$} & $\leq 46$ & 129 & 0.61 & $0.32-1.16$ \\
\hline & 47 to 67 & 256 & 0.75 & $0.44-1.27$ \\
\hline & $\geq 68$ & 133 & 1 & \\
\hline \multirow{2}{*}{ Previous type ${ }^{3}$} & Normal & 373 & 1 & \\
\hline & Atypical & 145 & $2.16^{* *}$ & $1.36-3.44$ \\
\hline
\end{tabular}

${ }^{1}$ Full model (B1, $\left.\mathrm{n}=1,049\right)$ was used unless otherwise stated.

${ }^{2}$ Weight loss was analyzed separately in a model (B3, $\left.\mathrm{n}=719\right)$ in which housing was omitted.

${ }^{3}$ Previous dry period length and previous type of progesterone profile were analyzed separately in a model $(\mathrm{B} 2, \mathrm{n}=518)$ in which parity and calving interval trial were omitted. $* P<0.05 ; * * P<0.01 ; * * * P<0.001$.

mainly by prolonged luteal phase profiles, for the $\mathrm{SH}$ cows compared with SRW cows supports this hypothesis. There has been a negative genetic trend in fertility for the $\mathrm{SH}$ breed, which is highly influenced by imported genetic material. In contrast, the genetic level has remained relatively constant in the SRW breed (Lindhé and Philipsson, 2001).

The higher risk of atypical profiles in first-parity cows was explained by a higher incidence of delayed cyclicity. We have previously shown that first-parity cows have later onset of cyclicity (Petersson et al., 2006). In earlier Swedish studies, later onset of ovarian activity in first- parity cows was reported, as well as a negative association with energy balance (Berglund et al., 1989). Lucy et al. (1992) showed that first-parity cows had a later first ovulation than later parity cows. This was apparently caused by the greater negative energy balance in first-parity cows than older cows. A higher incidence of delayed cyclicity was observed by Bulman and Wood (1980), although they also found an increased risk of atypical profiles in cows in their sixth to 11th lactation.

Cows in tie-stalls had a greater risk of atypical profiles than cows in loose housing; this was manifested in the form of increased proportions of cows having 
Table 3. Multinomial model with odds ratios, lower and upper 95\% confidence interval (CI) limits for the different profiles, and different systematic environmental effects for Swedish Holstein (SH) and Swedish Red and White (SRW) dairy $\operatorname{cows}^{1}$

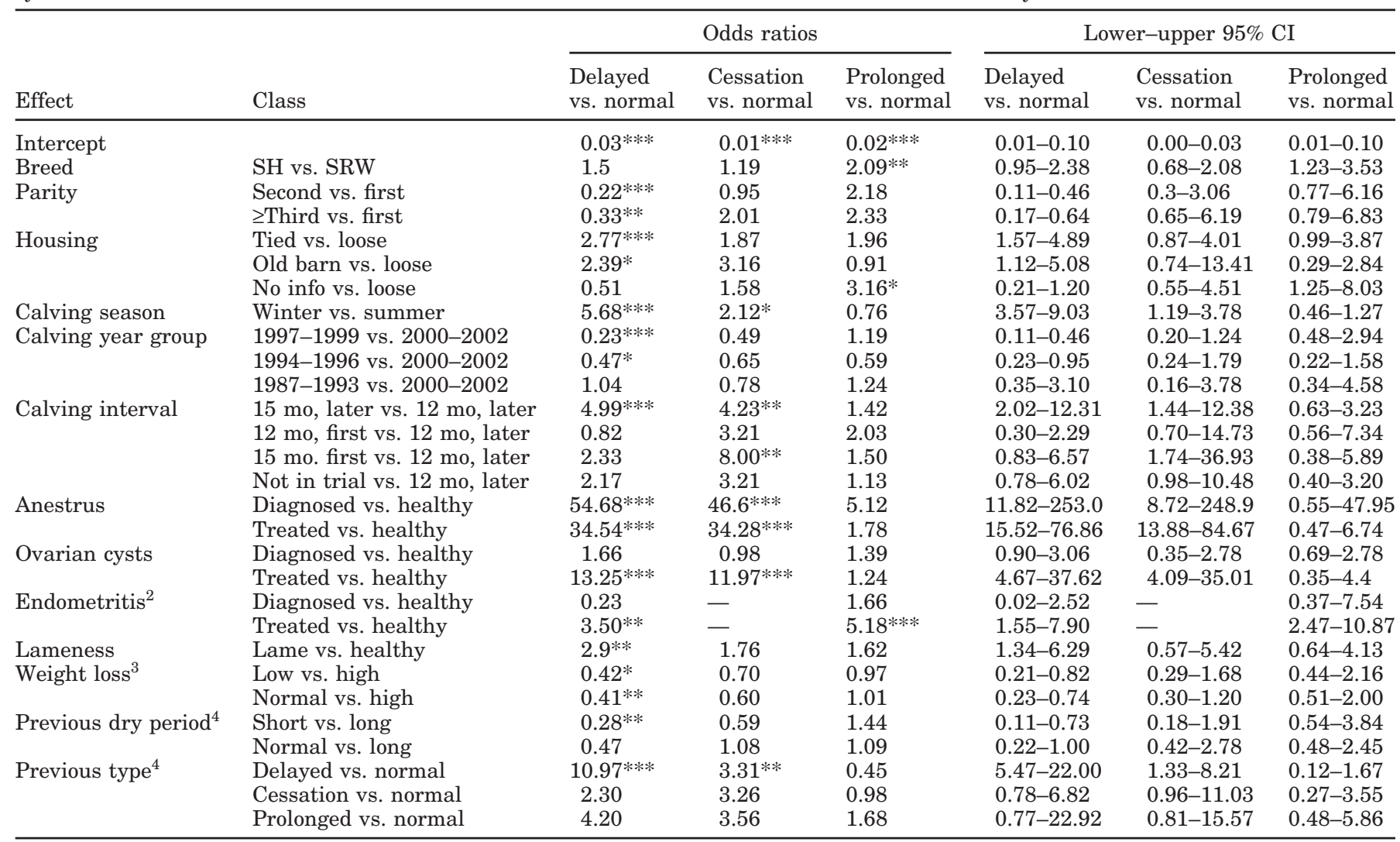

${ }^{1}$ Full model (M1a, $\mathrm{n}=1,049$ ) was used unless otherwise stated.

${ }^{2}$ In the model $(\mathrm{M} 1, \mathrm{n}=980$ ) with endometritis all observations with cessation were omitted owing to singularity problems in the analysis.

${ }^{3}$ Weight loss was analyzed separately in a model $(\mathrm{M} 3, \mathrm{n}=719)$ in which endometritis, housing and calving interval trial were omitted.

${ }^{4}$ Previous dry period length and previous type of progesterone profile were analyzed separately in a model (M2, $\left.\mathrm{n}=518\right)$ in which endometritis, anestrus, parity and calving interval trial were omitted.

$* P<0.05 ; * * P<0.01 ; * * * P<0.001$.

delayed cyclicity in tie-stalls. Intervals from calving to first ovulation were longer in tie-stalls than in loose housing (Claus et al., 1983) and confirmed in an earlier Swedish study using (in part) the same data (Ratnayake et al., 1998). We found that cows in tie-stalls had longer CLA and FOE (Petersson et al., 2006). Delayed cyclicity profiles were associated with both longer CLA and longer FOE in the present study (Table 5), indicating that loose housing has a more positive influence than tie-stalls on ovarian activity.

Table 4. Least squares means ( \pm SE) and number of observation for interval from calving to first service (CFI), calving to conception interval (CCI), and pregnancy to first AI (PFI) per type of profile in cows with conventional calving interval for Swedish Holstein and Swedish Red and White dairy cows ${ }^{1}$

\begin{tabular}{lrlrrr}
\hline & \multicolumn{5}{c}{ Fertility measure } \\
\cline { 2 - 6 } Profile & \multicolumn{1}{c}{ CFI (d) } & PFI (\%) & \multicolumn{1}{c}{$\mathrm{n}$} & \multicolumn{1}{c}{ CCI (d) } & \multicolumn{1}{c}{$\mathrm{n}$} \\
\hline Normal & $83.8 \pm 3.0^{\mathrm{a}}$ & $51.5 \pm 5.6$ & 483 & $97.2 \pm 5.0^{\mathrm{a}}$ & 398 \\
Delayed cyclicity & $100.4 \pm 3.7^{\mathrm{b}}$ & $45.1 \pm 7.0$ & 102 & $119.2 \pm 6.2^{\mathrm{b}}$ & 87 \\
Cessation of cyclicity & $96.9 \pm 4.8^{\mathrm{b}}$ & $51.3 \pm 9.2$ & 39 & $106.3 \pm 8.4^{\mathrm{ab}}$ & 31 \\
Prolonged luteal phase & $97.3 \pm 4.5^{\mathrm{b}}$ & $47.0 \pm 8.6$ & 47 & $113.2 \pm 8.4^{\mathrm{b}}$ & 32 \\
All atypical profiles & $98.8 \pm 3.2^{\mathrm{b}}$ & $46.9 \pm 6.0$ & 188 & $115.4 \pm 5.5^{\mathrm{b}}$ & 150 \\
\hline
\end{tabular}

${ }^{\mathrm{a}, \mathrm{b}}$ Different subscripts indicate differences $(P<0.05)$ between profiles within type of fertility measurement.

${ }^{1} \mathrm{CFI}$ and PFI had the same number of observations. 
Table 5. Mean ( \pm SE) per type of profile for interval from calving to commencement of luteal activity (CLA), interval from calving to first ovulatory estrus (FOE), and percentage of samples the first $60 \mathrm{~d}$ after calving above the limit for luteal activity (PLA) for Swedish Holstein and Swedish Red and White dairy cows

\begin{tabular}{llrr}
\hline Profile & CLA $(\mathrm{d})$ & \multicolumn{1}{c}{ FOE $(\mathrm{d})$} & \multicolumn{1}{c}{ PLA $(\%)$} \\
\hline Normal & $28.8 \pm 0.4^{\mathrm{a}}$ & $55.9 \pm 1.0^{\mathrm{a}}$ & $42.1 \pm 0.6^{\mathrm{a}}$ \\
Delayed cyclicity & $76.3 \pm 2.5^{\mathrm{b}}$ & $102.7 \pm 3.8^{\mathrm{b}}$ & $2.6 \pm 0.4^{\mathrm{b}}$ \\
Cessation of cyclicity & $29.4 \pm 1.7^{\mathrm{ad}}$ & $73.1 \pm 5.7^{\mathrm{c}}$ & $26.6 \pm 2.1^{\mathrm{c}}$ \\
Prolonged luteal phase & $25.4 \pm 1.5^{\mathrm{cd}}$ & $57.3 \pm 3.3^{\mathrm{a}}$ & $58.7 \pm 2.0^{\mathrm{d}}$ \\
\hline
\end{tabular}

${ }^{\mathrm{a}-\mathrm{d}}$ Different subscripts indicate differences $(P<0.05)$ between profiles within type of fertility measurement.

Cows that calved during the winter season (November to April) had an increased incidence of atypical profiles. The odds ratio rose significantly both for delayed cyclicity and cessation of cyclicity. An increased risk of delayed cyclicity for winter-calving cows was observed by Opsomer et al. (2000). A prolonged interval to first estrus during winter compared with summer was found by Hansen and Hauser (1983). In their study, diet or management did not affect the effect of calving season, so the effect was probably caused by photoperiod or temperature. In our study, we cannot exclude management or diet as probable causes of the seasonal effect, because the cows were on pasture from May to September and feed quality was different in the summer and winter calving seasons. In addition, temperature and photoperiod may be factors.

There was a significant increased risk of atypical profiles in the most recent calving year group (2000-2002) compared with the 2 preceding periods (1994-1996 and 1997-1999). This was dependent on an increased risk of delayed cyclicity. The proportion of atypical profiles in the first calving year group (1987-1993) did not differ from that in the other 3 groups. The increased distribution of atypical profiles in the last calving year group may be related to increased milk production or to the negative genetic trend for fertility that was observed in the Holstein breed (Lindhé and Philipsson, 2001). However, there was no association with milk production.

Cows with a planned extended calving interval of 15 mo had an increased incidence of atypical profiles, and especially of delayed cyclicity and cessation of cyclicity, provided that no selection bias was introduced unintentionally. This relationship was most pronounced in cows that already had one lactation with a planned extended calving interval. Because we have analyzed the profiles up to first AI, which is considerably later in cows with an extended calving interval, the increased study period is in itself a factor that might explain the higher probability of atypical profiles for this group. The result may be associated with a longer dry period in their previous lactation for cows with a 15-mo calving interval, which was shown by Rehn et al. (2000). An increased dry period was a risk factor for delayed ovulation (Opsomer et al., 2000). Currently, we found that the risk of delayed cyclicity was greater in cows with a dry period length in their previous lactation longer than $68 \mathrm{~d}$ than it was in cows with short ( $\leq 46 \mathrm{~d}$ ) dry period length.

All fertility disorders (anestrus, cysts, and endometritis) were associated with the various atypical progesterone profiles. This was expected, because diagnosis of anestrus and cystic ovaries are partly based on progesterone levels. Diagnosis of anestrus without treatment was associated with a higher incidence of delayed cyclicity and cessation of cyclicity. Diagnosis followed by treatment had an increased odds ratio, but at lower magnitude, for these 2 progesterone profiles. The lower association for treated cows was probably due to successful treatments early in lactation, because treated cows had a chance to recover and had a greater chance to display a normal progesterone profile.

Ovarian cysts are generally defined as large follicular structures that persist for at least $10 \mathrm{~d}$ in the absence of a corpus luteum. Concentrations of progesterone in plasma and milk are normally low in cows with follicular cysts and somewhat higher in cows with luteal cysts (Kesler and Garverick, 1982). We did not distinguish the 2 types of ovarian cysts. For ovarian cysts, there was an increased risk of delayed cyclicity and cessation of cyclicity only in cows that were both diagnosed and treated for cysts, indicating that it was generally a correct decision not to treat the majority of the diagnosed cysts, because they were associated with normal progesterone profiles.

Endometritis was associated with a prolonged luteal phase profile, and the odds ratio for treated cows was greater than it was in normal cows. Treated endometritis cases were associated with delayed cyclicity, but with lower odds ratio. Delayed cyclicity is probably due to uterine infections that delay the involution process and thereby impede ovarian activity (Kindahl et al., 1992). The prolonged luteal phases were associated with pyometra (Etherington et al., 1991).

The aggregated atypical profiles had no association with lameness. However, when the profiles were split into each category, there was a higher incidence of de- 
layed cyclicity in cows treated for lameness. We have previously shown a significantly later CLA and FOE in cows treated for lameness (Petersson et al., 2006). This agrees with Opsomer et al. (2000), who observed an increased risk of delayed cyclicity profiles in cows with clinical diseases including lameness. Similarly, Garbarino et al. (2004) showed an increased risk of delayed cyclicity in cows with lameness. Furthermore, Melendez et al. (2003) found that lameness within the first $30 \mathrm{~d}$ of calving reduces pregnancy rates at first $\mathrm{AI}$ and that lame cows become pregnant later and have a higher number of services per conception.

Cows with a decrease of more than $50 \mathrm{~kg}$ in BW during the first $8 \mathrm{wk}$ of lactation had an increased risk of delayed cyclicity profiles. Taylor et al. (2003) reported that cows with delayed cyclicity had the lowest BW and the greatest losses in BCS. Moreover, their cows with delayed cyclicity had long periods of negative energy balance.

In the current study, there was an increased risk of atypical progesterone profile if the cow had displayed an atypical profile in the previous lactation. A delayed profile in previous lactation increased the risk of a delayed profile in the subsequent lactation, but also increased the risk of cessation of cyclicity. These results indicate that some cows are more prone to atypical progesterone patterns than others. This is supported by the high heritabilities (16 to $20 \%$ ) for CLA found by Darwash et al. (1997), Royal et al. (2002), and Veerkamp et al. (2000).

Atypical profiles were associated with the traditional fertility measurements. Interval from calving to first AI was $15 \mathrm{~d}$ longer and CCI was $18 \mathrm{~d}$ longer in lactations with an atypical profile than in lactations with a normal profile. The longer CFI for atypical profiles was in agreement with the data of Royal et al. (2000), who found that CFI was $13 \mathrm{~d}$ longer for cows with an atypical progesterone profile compared with cows with no atypical pattern.

The major delay in CLA for delayed cyclicity was also reflected by a significantly longer FOE (Table 5). First ovulatory estrus was significantly later in lactations with cessation of cyclicity profile than it was in lactations with a normal profile, even if no difference was detected between these profiles with respect to CLA. Lactations with a prolonged luteal phase profile had a slightly earlier CLA than normal lactations, but were not statistically different in FOE.

The mean of PLA was different between all types of profile. We believe that this measurement could be utilized to obtain more information from the progesterone profile as compared with the CLA measurement. The main advantages of PLA over CLA are that PLA is probably easier to automate; it yields more informa- tion on what happens after cyclicity has started; and it can be used not only to separate delayed cyclicity profiles from normal profiles (as CLA can), but also to separate prolonged luteal phase profiles from normal profiles.

\section{CONCLUSIONS}

There was a higher incidence of atypical profiles in the Swedish Holsteins compared with Swedish Red and Whites. The proportion of atypical profiles increased in the last few years, mainly due to increased proportion of delayed cyclicity profiles. This, together with the increased risk of atypical profiles if a cow has an atypical profile in the previous lactation, is indicative of genetic influence on early postpartum fertility expressed by progesterone profiles. Abnormal progesterone profiles had a negative association with the traditional fertility measurements; both CFI and CCI were longer in lactations with an atypical profile. The PLA measurement (the percentage of progesterone samples taken within the first $60 \mathrm{~d}$ postpartum above the limit for luteal activity) gave a good estimate of what type of profile may be present. This measurement could be used to separate delayed cyclicity and prolonged luteal phase profiles from normal profiles, and might give PLA an advantage over CLA in the genetic evaluation of early postpartum fertility in dairy cows.

\section{ACKNOWLEDGMENTS}

This study was supported by the Swedish Farmers Research Council. The staff at the research farm is also gratefully acknowledged for their help with providing data for the study.

\section{REFERENCES}

Berglund, B., B. Danell, L. Janson, and K. Larsson. 1989. Relationships between production traits and reproductive performance in dairy cattle. Acta Agric. Scand. 39:169-179.

Bulman, D. C., and P. D. P. Wood. 1980. Abnormal patterns of ovarian activity in dairy cows and their relationships with reproductive performance. Anim. Prod. 30:177-188.

Claus, R., H. Karg, D. Zwiauer, I. von Butler, F. Pirchner, and E. Rattenberger. 1983. Analysis of factors influencing reproductive performance of the dairy cow by progesterone assay in milk-fat. Br. Vet. J. 139:29-37.

Darwash, A. O., G. E. Lamming, and J. A. Woolliams. 1997. Estimation of genetic variation in the interval from calving to postpartum ovulation of dairy cows. J. Dairy Sci. 80:1227-1234.

Etherington, W. G., K. A. Christie, J. S. Walton, K. E. Leslie, S. Wickstrom, and W. H. Johnson. 1991. Progesterone profiles in postpartum Holstein dairy cows as an aid in the study of retained fetal membranes, pyometra and anestrus. Theriogenology 35:731-746.

Garbarino, E. J., J. A. Hernandez, J. K. Shearer, C. A. Risco, and W. W. Thatcher. 2004. Effect of lameness on ovarian activity in postpartum Holstein cows. J. Dairy Sci. 87:4123-4131.

Hansen, P. J., and E. R. Hauser. 1983. Genotype x environmental interactions on reproductive traits of bovine females. III. Seasonal 
variation in postpartum reproduction as influenced by genotype, suckling and dietary regimen. J. Anim. Sci. 56:1362-1369.

Janson, L., and K.-Å. Ahlin. 1992. Postpartum reproductive performance in cattle selected for high and low fat content. Page 93 in Proc. 43rd Annu. Mtg., European Association for Animal Production (EAAP), Madrid, Spain.

Kesler, D. J., and H. A. Garverick. 1982. Ovarian cysts in dairy cattle: A review. J. Anim. Sci. 55:1147-1159.

Kindahl, H., K. Odensvik, S. Aiumlamai, and G. Fredriksson. 1992. Utero-ovarian relationships during the bovine postpartum period. Anim. Reprod. Sci. 28:363-369.

Lamming, G. E., and D. C. Bulman. 1976. The use of milk progesterone radioimmunoassay in the diagnosis and treatment of subfertility in dairy cows. Br. Vet. J. 132:507-517.

Lindhé, B., D.-A. Danielsson, G. Banos, L. Jansson, and J. Philipsson. 1994. Applied breeding policy 1981-1992 and its genetic effects in two Swedish dairy breeds. Publ. No. 111. Swedish Univ. Agric. Sci., Dept. Anim. Breed. Genet., Uppsala.

Lindhé, B., and J. Philipsson. 2001. Genetic trends in the two Swedish dairy cattle breeds SRB and SLB in 1985-1999. Publ. No. 138. Swedish Univ. Agric. Sci., Dept. Anim. Breed. Genet., Uppsala.

Lucy, M. C. 2001. Reproductive loss in high-producing dairy cattle: Where will it end? J. Dairy Sci. 84:1277-1293.

Lucy, M. C., C. R. Staples, W. W. Thatcher, P. S. Erickson, R. M. Cleale, J. L. Firkins, J. H. Clark, M. R. Murphy, and B. O. Brodie. 1992. Influence of diet composition, dry-matter intake, milk production and energy balance on time of post-partum ovulation and fertility in dairy cows. Anim. Prod. 54:323-331.

Melendez, P., J. Bartolome, L. F. Archbald, and A. Donovan. 2003. The association between lameness, ovarian cysts and fertility in lactating dairy cows. Theriogenology 59:927-937.

Opsomer, G., M. Coryn, H. Deluyker, and A. de Kruif. 1998. An analysis of ovarian dysfunction in high yielding dairy cows after calving based on progesterone profiles. Reprod. Domest. Anim. 33:193-204.

Opsomer, G., Y. T. Gröhn, J. Hertl, M. Coryn, H. Deluyker, and A. de Kruif. 2000. Risk factors for post partum ovarian dysfunction in high producing dairy cows in Belgium: A field study. Theriogenology 53:841-857.
Petersson, K.-J., E. Strandberg, H. Gustafsson, and B. Berglund. 2006. Environmental effects on progesterone profile measures of dairy cow fertility. Anim. Reprod. Sci. 91:201-214.

Ratnayake, D. R. T. G., B. Berglund, J. Bertilsson, M. Forsberg, and H. Gustafsson. 1998. Fertility in dairy cows managed for calving intervals of 12,15 or 18 months. Acta Vet. Scand. 39:215-228.

Rehn, H., B. Berglund, U. Emanuelsson, G. Tengroth, and J. Philipsson. 2000. Milk production in Swedish dairy cows managed for calving intervals of 12 and 15 months. Acta Agric. Scand., A Anim. Sci. 50:263-271.

Research Triangle Institute. 2004. SUDAAN Language Manual, Release 9.0. Research Triangle Inst., Research Triangle Park, NC.

Royal, M. D., A. O. Darwash, A. P. F. Flint, R. Webb, J. A. Woolliams, and G. E. Lamming. 2000. Declining fertility in dairy cattle: Changes in traditional and endocrine parameters of fertility. Anim. Sci. 70:487-501.

Royal, M. D., A. P. F. Flint, and J. A. Woolliams. 2002. Genetic and phenotypic relationships among endocrine and traditional fertility traits and production traits in Holstein-Friesian dairy cows. J. Dairy Sci. 85:958-967.

SAS Institute. 2001. SAS User's Guide. Version 8.2. SAS Institute Inc., Cary, NC.

Sjaunja, L.-O., L. Baevre, L. Junkkarinen, J. Pedersen, and J. Setälä. 1990. A Nordic proposal for an energy corrected milk (ECM) formula. Pages 156-157 in Proc. 27th Session of the International Committee for Animal Recording (ICAR), Paris, France.

Spörndly, R., ed. 1999. Fodertabeller för idisslare (Nutrition requirements for ruminants). Publ. No. 247. Swedish Univ. Agric. Sci., Dept. Anim. Nutr. Health, Uppsala.

Swedish Dairy Association. 2004. Husdjursstatistik (Cattle Statistics) 2004. Svensk Mjölk, Box 1146, 63180 Eskilstuna, Sweden.

Taylor, V. J., D. E. Beever, M. J. Bryant, and D. C. Wathes. 2003. Metabolic profiles and progesterone cycles in first lactation dairy cows. Theriogenology 59:1661-1677.

Veerkamp, R. F., J. K. Oldenbroek, H. J. van der Gaast, and J. H. J. van der Werf. 2000. Genetic correlation between days until start of luteal activity and milk yield, energy balance, and live weights. J. Dairy Sci. 83:577-583. 